PUBLIC HEALTH RESEARCH

\title{
Aduan Di Hospital Sultan Ismail Johor Bahru Dan Faktor Yang Mempengaruhi Tuntutan Pampasan
}

\author{
Azimatun Noor Aizuddin ${ }^{*}$, Surya Marsom ${ }^{1}$ and Hanuzah Omar ${ }^{2}$ \\ ${ }^{1}$ Department of Community Health, Faculty of Medicine, Universiti Kebangsaan Malaysia, Malaysia. \\ ${ }^{2}$ Department of Health Information, Hospital Canselor Tuanku Muhriz, Universiti Kebangsaan Malaysia, \\ Malaysia.
}

*For reprint and all correspondence: Azimatun Noor Aizuddin, ${ }^{1}$ Department of Community Health, Faculty of Medicine, Universiti Kebangsaan Malaysia, Malaysia.

Email: azimatunnoor@ppukm.ukm.edu.my

\section{ABSTRACT}

\begin{tabular}{|c|c|}
\hline & $\begin{array}{l}\text { Complaints in the health care system are complaints made by patients or } \\
\text { patient's relatives due to various reasons such as poor quality of service or } \\
\text { unmeet expectations. There are few studies done measuring the prevalence of } \\
\text { hospital's complaints but none being done in Hospital Sultan Ismail Johor } \\
\text { Bahru and very limited study looking at factors associated with it and with } \\
\text { compensation claims. This study aims to identify complaints at Hospital Sultan } \\
\text { Ismail Johor Bahru and factors associated with complaints and with } \\
\text { compensated claims. }\end{array}$ \\
\hline Methods & $\begin{array}{l}\text { A cross sectional study was done at Hospital Sultan Ismail Johor Bahru using } \\
\text { a data from } 1 \text { st January } 2009 \text { until } 31 \text { st December } 2016 \text {. All relevant data was } \\
\text { taken from the complaint data collected by the hospital Complaints } \\
\text { Management Committee. }\end{array}$ \\
\hline Results & $\begin{array}{l}\text { The study found a total of } 304 \text { complaints data with a prevalence of } 0.13 \text { per } \\
1000 \text { patient arrivals. Out of these complaints, } 16.7 \% \text { were compensation } \\
\text { claims. } 51.5 \% \text { of complainants were male and } 67.4 \% \text { were Malays. } 46.2 \% \text { of } \\
\text { complaints were related to clinical management, } 61.4 \% \text { were made against the } \\
\text { doctor. Only } 12.1 \% \text { complaints were related to mortality and } 11.4 \% \text { related to } \\
\text { morbidity. This study also found that there was significant relationship } \\
\text { between race, type of complaint and disease factor with complaints. }\end{array}$ \\
\hline Conclusions & $\begin{array}{l}\text { Compensation claims were highly related to clinical management and disease } \\
\text { factors. These complaints should investigate thoroughly to see what can be } \\
\text { done or to be improved in the future. }\end{array}$ \\
\hline & \\
\hline
\end{tabular}

Article history

Received: 12 August 2021

Accepted: 31 January 2022

Published: 1 March 2022 
ABSTRAK

Pengenalan Aduan dalam sistem rawatan kesihatan adalah aduan yang dibuat oleh pesakit atau saudara-mara pesakit kerana pelbagai alasan seperti kualiti perkhidmatan yang buruk atau harapan yang tidak dipenuhi. Terdapat beberapa kajian yang dilakukan untuk mengukur kadar aduan hospital tetapi tidak ada yang dilakukan di Hospital Sultan Ismail Johor Bahru dan kajian yang terhad dalam melihat aspek faktor-faktor yang berkaitan dengan aduan dan dengan tuntutan pampasan. Kajian ini bertujuan untuk mengenal pasti aduan di Hospital Sultan Ismail Johor Bahru dan faktor-faktor yang berkaitan dengannya serta faktorfaktor yang mempengaruhi tuntutan pampasan.

Metodologi Kajian ini menggunakan kaedah keratan rentas (cross sectional study). Data diambil dari jumlah aduan terkumpul oleh Jawatankuasa Pengurusan Aduan Hospital Sultan Ismail Johor Bahru bermula dari 1 Januari 2009 sehingga 31 Disember 2016.

Hasil Kajian Hasil kajian mendapati terdapat 304 data aduan dengan prevalens 0.13 per 1000 kedatangan pesakit. Seramai $16.7 \%$ pengadu telah membuat tuntutan pampasan. Kebanyakan pengadu adalah terdiri daripada lelaki $(51.5 \%)$ dengan (67.4\%) adalah berbangsa Melayu. Sejumlah (46.2\%) aduan adalah berkaitan pengurusan klinikal, $(61.4 \%)$ aduan dibuat terhadap perkhidmatan doktor manakala (12.1\%) aduan adalah berkaitan mortaliti dan (11.4\%) berkaitan morbiditi. Kajian ini juga mendapati terdapat hubungan di antara bangsa, jenis aduan dan faktor penyakit dengan tuntutan pampasan.

Kesimpulan Aduan berkaitan pengurusan klinikal dan faktor penyakit mempunyai hubungan signifikan dengan pengadu yang menuntut pampasan. Oleh itu, aduan ini harus disiasat secara menyeluruh untuk mengetahui apa yang perlu dilakukan atau diperbaiki supaya kejadian tidak berulang pada masa akan datang.

Kata Kunci Aduan - aduan pesakit - tuntutan pampasan. 


\section{PENGENALAN}

Aduan adalah ungkapan ketidakpuasan atau keadaan tidak boleh diterima yang dibuat oleh pelanggan kepada organisasi mengenai produk, perkhidmatan atau kakitangan mereka. ${ }^{1}$ Sesebuah organisasi atau individu yang menyediakan perkhidmatan kepada pelanggan adalah memang dijangka akan menerima aduan. $^{2}$

Aduan pesakit boleh menjadi beban kepada organisasi kesihatan tetapi pada masa yang sama ia juga dianggap sebagai sumber yang berharga untuk peningkatan kualiti dalam perkhidmatan kesihatan dan sumber maklumat yang berharga mengenai kekurangan dalam perkhidmatan. ${ }^{3}$ Bilangan aduan kepada penyedia perkhidmatan kesihatan telah menunjukkan peningkatan secara meluas berikutan pengiktirafan yang semakin meningkat terhadap hak pesakit di seluruh dunia. ${ }^{4}$

Keputusan sebuah kajian di Kanada menunjukkan bahawa daripada 1,375 jumlah aduan yang diterima sebanyak, $41 \%$ adalah berkaitan prestasi pentadbiran, $9 \%$ berhubung urusan laporan perubatan, 9\% mengenai etika , 38\% berkaitan kualiti penjagaan dan $2 \%$ adalah aduan yang tidak dapat dikelaskan. Satu kajian lain di Iran pada tahun 2002 melaporkan bahawa penyebab utama aduan adalah kecederaan fizikal sebanyak $27 \%$, kekurangan perhatian dan kecuaian (23\%), kematian $(22 \%)$, pembedahan yang tidak berjaya $(18 \%)$, dan salah diagnosis $(11 \%){ }^{4}$

Di negara kita sendiri Kementerian Kesihatan Malaysia telah melaporkan bahawa jumlah aduan yang diterima oleh Seksyen Medicolegal menunjukkan peningkatan dari tahun 2006 hingga 2011 dengan jumlah 1394 pada tahun 2011. Menurut Milton Lum, ahli lembaga Medical Defence Malaysia (MDM)juga menyatakan terdapat kenaikan bilangan litigasi terhadap doktor. Beliau juga mengatakan adanya peningkatan data kes litigasi terhadap doktor di Kementerian Kesihatan Malaysia daripada 29 kes (2006) kepada 56 (2011). ${ }^{5}$

Setiap aduan yang di terima akan melalui kaedah penyelesaian aduan secara berbeza-beza bergantung pada jenis aduan. Kebanyakan kaedah penyelesaian kes dapat dicapai dengan memuaskan. Permohonan maaf diterima sebagai jalan penyelesaian dalam kebanyakan kes aduan. Banyak pengarang telah melaporkan bahawa permohonan maaf yang dibuat secepat mungkin selepas aduan dibuat turut berhasil untuk memperbaiki keadaan dan mengurangkan masa dan sumber yang diperlukan untuk resolusi akhir. ${ }^{2}$

Adakalanya penyelesaian aduan berakhir dengan tuntutan pampasan. Pampasan adalah sejumlah wang yang diberikan kepada pesakit atau keluarga akibat kerugian, kerosakan atau kecederaan. Proses ini akan melalui Jabatan Kesihatan Negeri dan Kementerian Kesihatan Malaysia di mana proses siasatan dalaman yang dijalankan oleh fasiliti kesihatan terlibat aduan dan siasatan luar akan dilakukan untuk mencari penyelesaian. Siasatan luar adalah satu proses penyiasatan terhadap kes aduan yang dilaksanakan oleh suatu jawatankuasa dimana ahlinya dilantik dari anggota fasiliti kesihatan lain yang tidak terlibat dalam aduan tersebut. Jawatankuasa ini akan menulis laporan terperinci tentang hasil siasatan dan mencadangkan kepada Kerajaan Malaysia sama ada tuntutan pampasan layak dibayar kepada penuntut atau tidak. ${ }^{6}$

Ada juga aduan yang berupa litigasi .Litigasi akan membawa kepada tuntutan pampasan yang akan memberi kesan buruk kepada individu yang terlibat dalam aduan dan organisasi. ${ }^{7}$

Terdapat beberapa kajian tentang aduan terhadap fasiliti kesihatan yang telah dijalankan di Australia, United Kingdom dan Singapura, tetapi kajian berkaitan aduan kepada fasiliti kesihatan sangat terhad dilaksanakan di Malaysia dan belum ada di Hospital Sultan Ismail Johor Bahru. Kebanyakan kajian menentukan prevalens aduan hospital, sifat aduan, sosiodemografi pengadu, jabatan yang terlibat dan hasil aduan, namun tidak ada kajian yang dilakukan dalam menentukan faktor-faktor yang mempengaruhi aduan dan menyumbang kepada litigasi dan pampasan berikutan aduan. Selain itu dalam kajian ini, jumlah perbelanjaan yang dibelanjakan oleh Kementerian Kesihatan Malaysia untuk aduan yang melibatkan Hospital Ismail Johor Bahru juga akan dianalisa. Kajian ini dilaksanakan kerana alasan-alasan di atas.

\section{METODOLOGI}

Kajian ini dilakukan secara kaedah keratan rentas (cross- sectional study). Dalam reka bentuk kajian jenis ini, populasi dan sampel dipilih, dan data ini dikumpulkan untuk menjawab persoalan penyelidikan .

Kaedah pemilihan sampel adalah menggunakan kaedah pensampelan rawak mudah di mana data aduan yang telah dikumpulkan oleh Jawatankuasa Pengurusan Aduan Hospital Sultan Ismail Johor Bahru bermula daripada 1 Januari 2009 sehingga 31 Disember 2016 telah dipilih secara rawak. Pensampelan rawak mudah adalah cara pengambilan sampel dari sebuah populasi dengan cara tertentu sehingga setiap anggota populasi tadi memiliki peluang yang sama untuk terpilih atau terambil. ${ }^{8}$

Pengiraan saiz sampel adalah menggunakan 'epidinfo statcalculation sample size and power ' dengan saiz populasi 2200 , jangkaan frekuensi adalah $26 \%$ menurut kajian Taylor pada tahun 2004 , confidence level $0.8 \%$ dan penambahan sampel sebanyak $10 \%$. Jumlah sampel keseluruhan adalah $120+12=132$.

Kriteria kemasukan adalah semua aduan yang diterima oleh Jawatankuasa Pengurusan Aduan Hospital Sultan Ismail Johor Bahru bermula 1 Januari 2009 sehingga 31 Disember 2016. 
Sementara kriteria pengecualian adalah aduan yang diterima oleh Jawatankuasa Pengurusan Aduan Hospital Sultan Ismail dan dikategorikan sebagai aduan yang tidak relevan. Aduan tidak relevan adalah aduan yang tidak menepati tafsiran aduan mengikuti Garis panduan Pengurusan Aduan Awam Kementerian Kesihatan Malaysia .

\section{HASIL KAJIAN}

Jumlah keseluruhan aduan dari tahun 2009 hingga 2016 adalah sebanyak 304 sementara jumlah kedatangan pesakit ialah sebanyak 2,298,616. Prevalens aduan adalah 0.13 per 1000 kedatangan pesakit. Didapati jumlah aduan melibatkan tuntutan pampasan adalah sebanyak 22 kes iaitu $16.7 \%$ dari aduan di Hospital Sultan Ismail bagi tahun 2009 sehingga tahun 2016.

Jumlah pampasan yang telah dibayar kepada pengadu di Hospital Sultan Ismail Johor Bahru setakat dari tarikh 1 Januari 2009 sehingga 31 Disember 2016 adalah sejumlah RM 540,847.14.

Kebanyakan pengadu adalah terdiri daripada kaum lelaki (51.5\%) dan (67.4\%) adalah berbangsa Melayu. Aduan terbanyak yang diterima adalah berkaitan pengurusan klinikal iaitu pada kadar 46.2\%. Bagi kategori jawatan kakitangan yang diadu, $61.4 \%$ aduan adalah dibuat terhadap doktor diikuti dengan jururawat. Hanya $12.1 \%$ aduan adalah berkaitan mortaliti dan 11.4\% berkaitan morbiditi. Keputusan ini adalah seperti yang ditunjukkan dalam Jadual 1.

Jadual 1 Analisa deskriptif ciri-ciri sosio-demografi pengadu, jenis-jenis aduan, kategori jawatan dan faktor penyakit yang terlibat dalam aduan

\begin{tabular}{lrc}
\hline Kategori & $\begin{array}{r}\text { Frekuensi } \\
\mathrm{n}=132\end{array}$ & $\begin{array}{c}\text { Peratus } \\
\%\end{array}$ \\
\hline Jantina & 68 & 51.5 \\
Lelaki & 64 & 48.5 \\
Perempuan & & \\
Bangsa & 89 & 67.4 \\
Melayu & 19 & 14.4 \\
Cina & 24 & 18.2 \\
India & & \\
Jenis aduan & 61 & 46.2 \\
Pengurusan klinikal & 38 & 28.8 \\
Pentadbiran \& fasiliti & 33 & 25.0 \\
Hubungan & & \\
Kategori jawatan & 81 & 61.4 \\
Doktor & 11 & 8.3 \\
Jururawat & 23 & 17.4 \\
Pegawai Sains Kesihatan Bersekutu & 17 & 12.9 \\
Lain-lain & & \\
Faktor penyakit & 16 & 12.1 \\
Mortaliti & 15 & 11.4 \\
Morbiditi & 101 & 76.5 \\
Lain-lain & & \\
\hline
\end{tabular}

Jadual 2 menunjukkan hubungan antara sosiodemografi pengadu yang membuat tuntutan pampasan dan didapati bahawa peratusan kaum wanita yang menuntut pampasan adalah lebih tinggi berbanding dengan kaum lelaki .Walau bagaimanapun hubungan ini adalah tidak signifikan. Peratusan pengadu berbangsa India yang membuat tuntutan pampasan adalah lebih tinggi berbanding bangsa lain dan hubungan ini adalah signifikan $(p<$ $0.05)$.

Jadual 2 Menilai hubungan antara faktor sosiodemografi dengan aduan yang membuat tuntutan pampasan

\begin{tabular}{lcccc}
\hline Kategori & \multicolumn{2}{c}{ Tuntutan pampasan } & $\square^{2}$ & Nilai P \\
& $\begin{array}{c}\text { Ya } \\
(\mathrm{n}=22)\end{array}$ & $\begin{array}{c}\text { Tidak } \\
(\mathrm{n}=110)\end{array}$ & & \\
& $\mathrm{N}(\%)$ & $\mathrm{N}(\%)$ & & \\
\hline Jantina & & & & \\
Lelaki & $9(13.2)$ & $59(86.8)$ & 0.749 & 0.387 \\
Perempuan & $12(18.8)$ & $52(81.2)$ & &
\end{tabular}


International Journal of Public Health Research Vol 12 No 1 2022, pp (1519-1527)

\begin{tabular}{lllll} 
Bangsa & & & & \\
Melayu & $9(10.1)$ & $80(89.9)$ & 8.826 & 0.012 \\
Cina & $5(26.3)$ & $14(73.7)$ & & \\
India & $8(33.3)$ & $16(66.7)$ & & \\
\hline
\end{tabular}

Berdasarkan Jadual 3 berkaitan hubungan antara jawatan kakitangan dengan aduan yang membuat tuntutan pampasan, didapati bahawa peratusan doktor yang dikaitkan dengan tuntutan pampasan adalah lebih tinggi berbanding dengan jawatan lain. Walau bagaimanapun hubungan ini tidak signifikan.

Jadual 3 Menilai hubungan antara jawatan kakitangan dengan aduan yang membuat tuntutan pampasan

\begin{tabular}{lcccc}
\hline Jawatan Kakitangan & \multicolumn{2}{c}{ Tuntutan pampasan } & $\square^{2}$ & Nilai P \\
& Ya & Tidak & & \\
& $(\mathrm{n}=22)$ & $(\mathrm{n}=110)$ & & \\
& $\mathrm{N}(\%)$ & $\mathrm{N}(\%)$ & & 0.08 \\
\hline Doktor & $20(24.7)$ & $61(75.3)$ & 11.774 & \\
Jururawat & $2(18.2)$ & $9(81.8)$ & & \\
Lain - lain & $0(0)$ & $40(100)$ & & \\
\hline
\end{tabular}

Berdasarkan Jadual 4 hubungan antara jenis aduan dengan aduan yang membuat tuntutan pampasan, didapati bahawa faktor jenis aduan mempunyai hubungan yang signifikan dengan tuntutan pampasan $(p<0.05)$. Peratusan aduan melibatkan tuntutan pampasan adalah tinggi dalam kalangan aduan jenis pengurusan klinikal berbanding dengan aduan jenis komunikasi dan pentadbiran dan fasiliti.

Jadual 4 Menilai hubungan antara jenis-jenis aduan dengan aduan melibatkan tuntutan pampasan

\begin{tabular}{lcccc}
\hline Jenis Aduan & \multicolumn{2}{c}{ Tuntutan pampasan } & $\square^{2}$ & Nilai P \\
& Ya & Tidak & & \\
& $(\mathrm{n}=22)$ & $(\mathrm{n}=110)$ & & \\
& $\mathrm{N}(\%)$ & $\mathrm{N}(\%)$ & & $<0.001$ \\
\hline Pengurusan klinikal & $20(32.8)$ & $41(67.2)$ & 21.571 & \\
Hubungan & $2(5.3)$ & $36(94.7)$ & & \\
Pentadbiran \&fasiliti & $0(0)$ & $33(100)$ & & \\
\hline
\end{tabular}

Berdasarkan Jadual 5, hubungan antara faktor penyakit dengan aduan yang melibatkan tuntutan pampasan, didapati bahawa faktor penyakit mempunyai hubungan yang signifikan dengan tuntutan pampasan $(p<0.05)$. Peratusan aduan yang melibatkan tuntutan pampasan adalah tinggi dalam kalangan faktor mortaliti berbanding dengan morbiditi dan lain-lain.

Jadual 5 Menilai hubungan antara faktor penyakit dengan aduan yang membuat tuntutan pampasan

\begin{tabular}{|c|c|c|c|c|}
\hline \multirow{2}{*}{$\begin{array}{l}\text { Faktor } \\
\text { penyakit }\end{array}$} & \multicolumn{2}{|c|}{ Tuntutan Pampasan } & $\square^{2}$ & Nilai P \\
\hline & $\begin{array}{c}\mathrm{Ya} \\
(\mathrm{n}=22) \\
\mathrm{N}(\%)\end{array}$ & $\begin{array}{c}\text { Tidak } \\
(\mathrm{n}=110) \\
\mathrm{N}(\%)\end{array}$ & & \\
\hline Mortaliti & $9(56.3)$ & $7(43.8)$ & 42.552 & $<0.001$ \\
\hline Morbiditi & $8(53.3)$ & $7(46.7)$ & & \\
\hline Lain-lain & $5(5.0)$ & $96(96)$ & & \\
\hline
\end{tabular}

Jadual 6 menunjukkan hubungan antara sosiodemografi pengadu yang menerima bayaran tuntutan pampasan dan didapati bahawa peratusan pengadu lelaki yang menerima bayaran menuntut pampasan adalah lebih tinggi berbanding dengan pengadu perempuan.Walau bagaimanapun hubungan ini adalah tidak signifikan. Peratusan pengadu berbangsa Cina yang menerima bayaran tuntutan pampasan adalah lebih tinggi berbanding bangsa lain namun hubungan ini adalah tidak signifikan. 


\section{Tuntutan pampasan}

Jadual 6 Menilai hubungan antara faktor sosiodemografi pengadu dengan aduan yang menerima bayaran tuntutan pampasan

\begin{tabular}{lcccc}
\hline Kategori & \multicolumn{2}{c}{ Terima Bayaran } & $\square^{2}$ & Nilai P \\
& $\begin{array}{c}\text { Tuntutan pampasan } \\
\text { Ya }\end{array}$ & Tidak & & \\
& $\begin{array}{c}\mathrm{n}=13) \\
\mathrm{N}(\%)\end{array}$ & $\begin{array}{c}\mathrm{n}=119) \\
\mathrm{N}(\%)\end{array}$ & & \\
\hline Jantina & & & & \\
Lelaki & $7(10.2)$ & $61(89.7)$ & 0.31 & 0.859 \\
Perempuan & $6(9.4)$ & $58(90.6)$ & & \\
Bangsa & & & & \\
Melayu & $7(7.9)$ & $82(92.1)$ & 1.34 & 0.512 \\
Cina & $3(15.8)$ & $16(84.2)$ & & \\
India & $3(12.5)$ & $21(87.5)$ & & \\
\hline
\end{tabular}

Berdasarkan Jadual 7 berkaitan hubungan antara jawatan kakitangan dengan aduan yang menerima bayaran tuntutan pampasan, didapati bahawa peratusan aduan yang berkaitan dengan jururawat adalah lebih tinggi menerima bayaran tuntutan pampasan berbanding dengan jawatan lain. Walau bagaimanapun hubungan ini tidak signifikan.

Jadual 7 Menilai hubungan antara faktor jawatan kakitangan dengan aduan yang menerima bayaran tuntutan pampasan

\begin{tabular}{|c|c|c|c|c|}
\hline \multirow[t]{2}{*}{ Jawatan Kakitangan } & \multicolumn{2}{|c|}{$\begin{array}{c}\text { Terima bayaran tuntutan } \\
\text { pampasan }\end{array}$} & \multirow[t]{2}{*}{$\square^{2}$} & \multirow[t]{2}{*}{ Nilai P } \\
\hline & $\begin{array}{c}\mathrm{Ya} \\
(\mathrm{n}=13) \\
\mathrm{N}(\%)\end{array}$ & $\begin{array}{c}\text { Tidak } \\
(\mathrm{n}=119) \\
\mathrm{N}(\%)\end{array}$ & & \\
\hline Doktor & $11(13.8)$ & $70(86.3)$ & 6.50 & 0.90 \\
\hline Jururawat & $2(18.2)$ & $9(81.8)$ & & \\
\hline Lain - lain & $0(0)$ & $40(100)$ & & \\
\hline
\end{tabular}

Jadual 8 menunjukkan hubungan antara jenis aduan dengan aduan yang menerima bayaran tuntutan pampasan, didapati bahawa faktor jenis aduan pengurusan klinikal mempunyai hubungan yang signifikan dengan bayaran tuntutan pampasan $(p<0.05)$. Peratusan aduan menerima bayaran tuntutan pampasan adalah tinggi dalam kalangan aduan jenis pengurusan klinikal berbanding dengan aduan jenis hubungan, pentadbiran dan fasiliti.

Jadual 8 Menilai hubungan antara jenis-jenis aduan dengan aduan yang menerima bayaran tuntutan pampasan

\begin{tabular}{lcccc}
\hline Jenis Aduan & \multicolumn{2}{c}{ Terima bayaran tuntutan } & $\square^{2}$ & Nilai P \\
& \multicolumn{2}{c}{ pampasan } & & \\
& Ya & Tidak & & \\
& $\mathrm{n}=13)$ & $(\mathrm{n}=119)$ & & \\
\hline Pengurusan klinikal & $13(21.3)$ & $\mathrm{N}(\%)$ & & \\
Hubungan & $0(0)$ & $38(78.7)$ & 16.78 & $<0.001$ \\
Pentadbiran \&fasiliti & $0(0)$ & $33(100)$ & & \\
\hline
\end{tabular}

Berdasarkan Jadual 9, hubungan antara faktor penyakit dengan aduan yang menerima bayaran tuntutan pampasan, didapati bahawa faktor penyakit mempunyai hubungan yang signifikan dengan aduan yang menerima tuntutan pampasan ( $p$
$<0.05)$. Peratusan aduan yang melibatkan bayaran tuntutan pampasan adalah tinggi dalam kalangan faktor mortaliti berbanding dengan faktor morbiditi dan lain-lain. 
International Journal of Public Health Research Vol 12 No 1 2022, pp (1519-1527)

Jadual 9 Menilai hubungan antara faktor penyakit dengan aduan yang menerima bayaran tuntutan pampasan

\begin{tabular}{|c|c|c|c|c|}
\hline \multirow[t]{2}{*}{$\begin{array}{l}\text { Faktor } \\
\text { penyakit }\end{array}$} & \multicolumn{2}{|c|}{$\begin{array}{l}\text { Terima bayaran tuntutan } \\
\text { pampasan }\end{array}$} & \multirow[t]{2}{*}{$\square^{2}$} & \multirow[t]{2}{*}{ Nilai P } \\
\hline & $\begin{array}{c}Y a \\
(n=13) \\
N(\%)\end{array}$ & $\begin{array}{c}\text { Tidak } \\
(\mathrm{n}=119) \\
\mathrm{N}(\%)\end{array}$ & & \\
\hline Mortaliti & $6(37.5)$ & $10(43.8)$ & 30.14 & $<0.001$ \\
\hline Morbiditi & $5(33.3)$ & $10(46.7)$ & & \\
\hline Lain-lain & $2(1.9)$ & $99(98.1)$ & & \\
\hline
\end{tabular}

\section{PERBINCANGAN}

Prevalens aduan di Hospital Sultan Ismail Johor Bahru adalah sebanyak 0.13 per 1000 kedatangan pesakit. Jumlah ini adalah rendah dibandingkan dengan beberapa kajian terdahulu yang dilakukan di beberapa negara lain. Kajian yang dilakukan oleh Anderson et al pada tahun 2001 di hospital major Australia yang menunjukkan bahawa kadar aduan di hospital tersebut adalah 1.12 per 1000 lawatan. Sebuah kajian lain di Mount Isa Health Service District Australia juga menunjukkan prevalens aduan 0.21 per 1000 lawatan. ${ }^{9}$. Prevalens aduan yang rendah di Hopital Sultan Ismail ini juga disokong oleh kajian di Singapura iaitu kajian oleh Wong et al pada tahun 2007 di jabatan kecemasan hospital National University, Singapura mendapati bahawa prevalens aduan hospital adalah 1.17 bagi setiap 1000 kunjungan pesakit. ${ }^{10}$ Prevalens kes aduan yang ditemui dalam kajian ini adalah lebih rendah berbanding dengan kadar yang dilaporkan oleh penyelidik lain.

Prevalens aduan di Hospital Sultan Ismail ini rendah mungkin disebabkan oleh pelbagai faktor. Antaranya ialah kemungkinan pesakit dan pelanggan berpuas hati dengan rawatan yang diberikan sehingga tiada aduan dibuat. Faktor lain adalah mungkin pesakit atau pelanggan tidak tahu cara untuk menyalurkan aduan walaupun tidak berpuashati dengan rawatan dan layanan yang diterima sehingga rasa tidak puas hati itu tidak disuarakan. ${ }^{11}$

Bilangan pengadu lelaki (51.5\%) dalam kajian ini adalah lebih tinggi berbanding perempuan (48.5\%). Hasil ini tidak selari dengan kajian yang dilakukan oleh pada tahun 2010 di Kanada ${ }^{12}$ dan di Australia di mana prevalens pengadu perempuan lebih tinggi berbanding lelaki. ${ }^{2}$ Kajian yang dilakukan oleh Kathryn et al ${ }^{6}$ pada tahun 2001 juga menyatakan pengadu adalah lebih tinggi dalam kalangan wanita dengan peratusan sebanyak 54\%.

Pengadu adalah lebih tinggi dalam kalangan bangsa Melayu berbanding bangsa Cina dan India iaitu sebanyak 67.4\%. Ini mungkin kerana bangsa Melayu adalah penduduk yang paling ramai di daerah Johor Bahru. Penduduk Melayu sebanyak $47.5 \% \quad(802,750$ orang penduduk), Cina $34.2 \%$ $(577,980), 9.0 \%$ India $(152,100), 0.6 \%(10,014)$ dan minoriti lain $8.7 \%(147,030)$ bukan warganegara. ${ }^{14}$
Jenis aduan diklasifikasikan kepada tiga kumpulan utama mengikut taxonomi aduan menurut Reader et al. ${ }^{13}$ Klasifikasi tersebut adalah pengurusan klinikal, pentadbiran dan fasiliti serta komunikasi atau hubungan antara kakitangan dan pesakit. Hasil kajian menunjukkan aduan adalah tinggi dari kalangan jenis aduan berkaitan pengurusan klinikal berbanding-jenis aduan yang lain. Ini adalah selari dengan kajian yang dilakukan di sebuah hospital di Singapura di mana aduan berkaitan pengurusan klinikal adalah sebanyak $76 \%$. ${ }^{9}$ Sebaliknya kajian lain yang dilakukan di Mount Isa Health Service District Australia pada tahun 2009 mendapati aduan jenis komunikasi adalah paling tinggi iaitu sebanyak $60 \%{ }^{8}$

Hasil kajian menunjukkan kategori jawatan doktor menerima aduan terbanyak iaitu sebanyak 61.4 peratus diikuti dengan pegawai Sains Kesihatan Bersekutu, jururawat dan lain-lain. Hasil kajian ini adalah selari dengan kajian yang dilaksanakan di sebuah hospital Iran di mana majoriti aduan (62\%) adalah melibatkan doktor dan selebihnya adalah jururawat $(10 \%){ }^{4}$ Hasil kajian juga mendapati hanya $12.1 \%$ melibatkan mortaliti, $11.4 \%$ adalah morbiditi dan selebihnya adalah melibatkan faktor penyakit lain.

Hubungan antara jantina pengadu dengan aduan yang membuat tuntutan pampasan adalah tidak signifikan. Hasil kajian juga menunjukkan bahawa pengadu berbangsa India adalah yang paling ramai membuat tuntutan pampasan dan terdapat hubungan yang signifikan antara bangsa pengadu dengan aduan yang melibatkan tuntutan pampasan di mana $p<0.05$. Walau bagaimanapun tiada hasil kajian lain sebelum ini yang boleh dibuat perbandingan tentang dapatan ini.

Kajian juga mendapati tiada hubungan yang signifikan antara jawatan kakitangan yang mendapat aduan dengan aduan yang membuat tuntutan pampasan

Hubungan antara jenis aduan dengan aduan yang membuat tuntutan pampasan, didapati bahawa faktor jenis aduan mempunyai hubungan yang signifikan dengan tuntutan pampasan. Peratusan aduan yang menuntut pampasan adalah tinggi dalam kalangan aduan jenis pengurusan klinikal berbanding dengan aduan jenis komunikasi serta pentadbiran dan fasiliti. 
Dalam kajian ini hubungan antara faktor penyakit dengan aduan yang membuat tuntutan pampasan, didapati bahawa faktor penyakit mempunyai hubungan yang signifikan dengan tuntutan pampasan. Peratusan aduan yang menuntut pampasan adalah tinggi dalam kalangan faktor mortaliti berbanding dengan morbiditi dan lain-lain. Hasil kajian ini adalah tidak selari dengan kajian yang dilaksanakan di hospital-hospital awam di New Zealand pada tahun 2006 dimana kajian tersebut mendapati bahawa kadar aduan pesakit meningkat dengan keterukan kecederaan dan kemungkinan aduan pesakit dari kecederaan serius ialah 11 kali lebih tinggi daripada yang kecil, dan 18 kali lebih besar selepas kematian. ${ }^{15}$

Hasil kajian ini juga mendapati bahawa terdapat hubungan yang signifikan di antara faktor jenis aduan dan faktor penyakit dengan aduan yang menerima bayaran pampasan.

\section{KESIMPULAN}

Sebagai kesimpulan sesebuah organisasi adalah sangat digalakkan untuk mengenalpasti faktorfaktor yang mempengaruhi tuntutan pampasan sebagai usaha untuk mengurangkan prevalens aduan di organisasi tersebut. Faktor jenis aduan berkaitan pengurusan klinikal dan faktor penyakit didapati mempunyai hubungan signifikan dengan aduan yang menuntut pampasan. Faktor-faktor ini adalah faktor yang boleh diambil kira sebagai kelemahan organisasi yang boleh diperbaiki kerana keduanya berkait rapat dengan proses perawatan dan penjagaan pesakit yang merupakan tugas utama sebuah fasiliti kesihatan. Dengan mengetahui hasil kajian ini, amatlah penting bagi setiap kakitangan yang terlibat dengan perawatan pesakit secara langsung untuk mematuhi dan mempraktikkan setiap langkah dalam perawatan mengikut Standard Operating Procedure (SOP) yang telah digariskan oleh Kementerian Kesihatan Malaysia. Selain itu kakitangan klinikal juga haruslah dipastikan sentiasa mempunyai pengetahuan rawatan yang terkini bagi memastikan kualiti penjaga pesakit terjamin.Latihan dalam perkhidmatan kakitangan klinikal adalah dicadangkan untuk sentiasa dilaksanakan secara berkala bagi mengelakkan kesilapan dalam melaksanakan proses rawatan.

Selain itu, walaupun prevalens aduan di Hospital Sultan Ismail Johor Bahru masih termasuk dalam kategori rendah, keadaan ini perlu sentiasa dikekalkan bagi mengelakkan terjadinya peningkatan aduan di masa akan datang.

\section{RUJUKAN}

1. Ombudsman Western Australia. Effective handling of complaints made to your organization. Australia; 2017.

2. Taylor DM, Wolfe RS \& Cameron PA. Analysis of complaints lodge by patient attending Victorian Hospital 1997-2001. Medical Journal Australia. 2004; 181:5-31.

3. Anel-Rodriguez Cambero-Serrano MI \& Irurzun-Zuazabal E. Analysis of patient complains in Primary Care: An opportunity to improve clinical safety. Revista De Calidad Asistencial. 2015; 30(5): 220-225.

4. Ebrahimipour H, Vafaee-Najar A, Khanijahani A, Pourtaleb A, Saadati Z, Molavi Y \& Kaffashi S. Customers' Complaints and Its Determinants: The Case of a Training Educational Hospital in Iran. International Journal of Health Policy and Management. 2013;1(4): 273-277.

5. Siti Naaishah H \& Solmaz K. Review of Medical Malpractice Issues in Malaysia under Tort Litigation System. Journal of Health Science. 2014;6(4): 76-83.

6. Portal Rasmi Biro Pengaduan Awam. Jabatan Perdana Menteri. http://www.pcb.gov.my/bm/aduan/sistempengurusan-aduan-awam-sispaa; 2013 [Diakses pada 9 Oktober 2018].

7. Kathryn A, Deidre ARN \& Paul F. A 30month study of patient complaints at a major Australian hospital. Journal of Quality Clinical Practice. 2001;21: 109111.

8. Pengertian_Simple_Random; 2018 Didapati di: https://www.statistikian.com. [Diakses pada 30 Ogos 2021].

9. Julianne $\mathrm{P} \&$ Udul H. Investigating complaints to improve practice and develop policy. International Journal of Health Care Quality Assurance. 2009; 22(7): 663-669.

10. Wong LL, Oii SBS \& Goh LG. Patient's complaints in a hospital emergency department in Singapore. Singapore Medical Journal. 2007; 48(11): 990-995.

11. Howard BB, Kathryn MM, Anthony LS \& Richard MF. The Doctor-Patient Relationship and Malpractice Lessons from Plaintiff Depositions. Arch Intern Med.154 $.1994 ;(12): 1365-1370$.

12. Mailis-Gagnon A, Nicholson $\mathrm{K}$ \& Chaparro L. Analysis of complaints to a tertiary care pain clinic over a nine-year period. Pain Research Management. 2010; 15(1): 17-23.

13. Tom WR, Alex G \& Jane R. Patient complaints in healthcare systems: a systematic review and coding taxonomy. BMJ Quality and Safety. 2014; 23:678-68.

14. Statistics Department, Malaysia. Total population by ethnic group, Local Authority area and state, Kuala Malaysia; 2010.

15. Bismark MM, Brennan TA, Peterson RJ, Davis PB \& Studdert DM. Relationship between complaints and quality of care in 
International Journal of Public Health Research Vol 12 No 1 2022, pp (1519-1527)

New Zealand: A descriptive analysis of complainants and non-complainants following adverse events. British Medical Journal. 2006. Didapati di:

http://dx.doi.org/10.1136/qshc.2005.01574

3 [Diakses pada16 October 2018]. 